\title{
Using the ACAT Framework to evaluate the design of two geometry apps: An exploratory study.
}

Authors

Kevin Larkin. School of Education and Professional Studies, Griffith University, Gold Coast, Australia.

Email: k.larkin@griffith.edu.au

Phone: +61428 566708

Orcid: 0000-0002-8704-1272

Ulrich Kortenkamp. Institute of Mathematics, Potsdam University, Germany.

Silke Ladel. University of Education Schwäbisch Gmünd, Germany.

Heiko Etzold. Institute of Mathematics, Potsdam University, Germany.

\begin{abstract}
It is an increasingly common phenomenon that elementary school students are using mobile applications (apps) in their mathematics classrooms. Classroom teachers using apps might benefit from a tool, or a set of tools, to help them determine whether or not a given app is appropriate and how enhanced educational outcomes can be achieved via its use. In this article we investigate whether Artifact Centric Activity Theory (ACAT) can be used to create a useful tool for evaluating apps, present a review guide based on the theory and test it using a randomly selected geometry app [Pattern Shapes] based on unknown design principles that may or may not conform to design principles suggested in the research as best practice. In doing so we broaden the scope of ACAT by investigating [Pattern Shapes], an app that has additional requirements in terms of accuracy of external representations, and depictions of mathematical properties (e.g. rotations, symmetry), than is the case for place value concepts in [Place Value Chart] which was created using ACAT principles and has been the primary app evaluated using ACAT. We further expand the use of ACAT via an independent assessment of a second app [Click the Cube] by a novice, using the ACAT review guide. Based on our latest research, we argue that ACAT is highly useful for evaluating any mathematics learning app and this is a critical contribution if the evaluation of apps is to move beyond academic circles and start to impact student learning and teacher choice in mathematics classrooms.
\end{abstract}

Keywords: Mathematics education; Mathematics apps; Activity Theory; Artifact-Centric Activity Theory; geometry; App design; App reviews 


\section{Using the ACAT Framework to evaluate the design of two geometry apps: An exploratory study.}

\section{Introduction}

It is an increasingly common phenomenon that primary / elementary school students are using mobile applications (apps) in their mathematics classrooms. Classroom teachers, who are either using apps, or in some cases designing apps, could derive additional benefit from a tool, or a set of tools, to help them determine whether or not apps are appropriate and how enhanced educational outcomes can be achieved via their use.

In earlier articles and book chapters, Ladel and Kortenkamp (2011; 2012; 2013; 2016) have outlined the creation of a theoretical framework, Artifact Centric Activity Theory (ACAT), as a mechanism for understanding the various interactions that occur when students use multi-touch environments (Ladel and Kortenkamp 2011; 2013) or a specific app [Place Value App] (Ladel and Kortenkamp 2013) (See Fig 3). ACAT is based on Activity Theory (Leontiev 1978) and is an evolution of Activity Systems (Engeström 1987). It is useful as a methodological tool to understand and structure the complex, causal network of relationships that comprises the interacting activity system of teaching and learning. The causal network consists of five components (subject, artifact, object, rules, group) that mutually affect, and are affected by, each other. The artifact is positioned centrally in the ACAT model as it is the focal point of the processes of internalization and externalization between subject and object. Ladel and Kortenkamp (2016) argue that the framework provides valuable pedagogical information for teachers in using apps with students, and also provides a set of design principles for app developers who want to create mathematically and pedagogically appropriate apps.

Research into app quality using methodologically and conceptually robust tools is important for a number of reasons. Firstly, determining the quality of an app is difficult not only due to a lack of current research, but also because the information that is available at either the iTunes Appstore or Google Play is supplied by app developers and largely serves as an infomercial (Larkin 2013). Secondly, apart from a small number of theoretically rigorous reviews (e.g. Larkin 2015; MoyerPackenham et al. 2016; Namukasa, Gadanidis, Sarina, Scucuglia and Aryee 2016) many reviews of apps provided on websites such as (http://www.teachthought.com/the-future-oflearning/technology/12-of-the-best-math-apps-for-kids/), or in conference proceedings (e.g. Highfield and Goodwin 2013), are often generic in nature. Thirdly, most cited research (the authors included) are reviews of apps based on evaluations conducted by the authors of the reviews or based on apps created by the authors, rather than on evaluations of independent reviewers. Finally, there are no studies that we are aware of that have investigated evaluative tools in relation to their subsequent impact on teacher knowledge and instructional approaches.

As noted earlier, although ACAT has been thoroughly investigated in previous publications, this article develops the use of this theory, as outlined in detail in the remainder of this paragraph, in three ways. Firstly, to this point, ACAT has primarily been used to explain the creation and use of [Place Value Chart]; in this article, we therefore investigate whether ACAT is a useful tool for evaluating two geometry apps [Pattern Shapes] and [Click the Cube] which are built upon different (if 
any at all) design principles. The app [Pattern Shapes] was randomly selected from a broader review of ACAT might be used by educators and researchers to evaluate the quality of apps in developing geometry concepts or skills. In the previous studies, [Pattern Shapes] was evaluated as a top quality app according to the three diagnostic measures used (See Larkin, 2016). Secondly, we broaden the scope of ACAT by investigating geometry apps that have additional requirements beyond those often associated with number apps. These additional requirements relate to accuracy of external representations and depictions of mathematical properties (e.g. transformations, co-ordinate geometry, angles and symmetry). Thirdly, we broaden the prospective usefulness of ACAT by reporting on how an independent, non-academic evaluator used the ACAT review guide explored in this article (See Appendix One) to assess the quality of [Click the Cube] (See Appendix Two). This is a critical consideration if the evaluation of apps is to move beyond academic circles into the teaching profession.

\section{Literature Review}

Although the use of mathematics apps is relatively recent, there is a long history of the use of manipulatives, concrete and more recently digital, in mathematics education in general (e.g. MoyerPackenham, Salkind and Bolyard 2008) and geometry in particular (e.g. Sinclair and Bruce 2015). In this brief review we synthesize extant literature in the domains of geometry, digital manipulatives, and the methods that various researchers have used to evaluate the effectiveness of digital manipulatives in mathematics education. We also discuss Activity Theory, the progenitor of ACAT, and establish how ACAT is an important adaptation of Activity Systems in understanding the role of digital manipulatives in mathematics education.

Geometry is a core content component of primary mathematics education and has strong connections with most other mathematics strands (Alqahtani and Powell 2017). It is broadly defined in most curricula documents as a branch of mathematics dealing with size, shape, position and properties of space. By way of example, the Australian Curriculum (ACARA) offers geometry (including sub-strands such as Shape, Transformation and Location, and Geometric Reasoning) as one of six core Mathematics strands from Foundation (i.e. Kindergarten) until Year 10 (ACARA 2012). Likewise, the German national educational standards (KMK) offers geometry (including sub-strands such as Space and Form, Measurement, Transformation, and Spatial Reasoning) as one of five core mathematics standards from primary (Year 1-4) to secondary (Year 5-13) school education (KMK 2003). In the United States context, the National Council of Teachers of Mathematics (NCTM) reinforces the critical role of geometry in the overall learning of mathematics and calls on teachers to offer students the opportunity to "analyse characteristics of geometric shapes and make mathematical arguments about the geometric relationship, as well as to use visualization, spatial reasoning, and geometric modeling to solve problems" (NCTM 2018, NP).

Contemporary research has linked geometric understanding to a range of mathematical concepts including, for example, patterning and algebraic reasoning (Papic, Mulligan and Mitchelmore 2011) as well as more broadly to other school disciplines (Sinclair \& Bruce, 2015). Work in the field of cognitive psychology establishes very clear correlations between spatial reasoning and overall mathematics achievement (Lowrie, Logan and Ramful 2017) and also later success in the 
mathematically related fields of Science, Technology and Engineering (Uttal and Cohen 2012). approaches available for teaching geometry.

\section{Virtual manipulatives in mathematics education}

Manipulatives have long played a critical role in the teaching and learning of mathematics, and activities using manipulatives form the basis for enhancing a range of mathematical learning processes. Operations using manipulatives are purposeful and it is essential that students are aware of the relations between the objects and the concepts they are learning. In this regard, manipulatives do not necessarily have to be of a physical nature but can be virtual as well (Clements 1999; Ladel 2009) and there is a growing body of evidence indicating that quality apps can support mathematical learning (Ladel and Kortenkamp 2016).

Although the use of manipulatives is seen as beneficial to student learning of mathematics, this shouldn't be interpreted as a blanket endorsement of manipulatives (concrete or digital) as a panacea for mathematics education. For example, (Larkin, 2016) argued that careful selection of manipulatives is required to support student learning and that using manipulatives that have been poorly designed can be detrimental for student learning. Uttal (2003) in evaluating concrete manipulatives, makes a similar observation stating "manipulatives cannot be used in isolation. Simply playing with a manipulative is unlikely to help children learn information that will facilitate their understanding of written representations. Indeed, it may sometimes be counterproductive" (Uttal, 2003, p. 109). Pimm (1995) goes further in suggesting that digital manipulatives is markedly changing the relationship children have between symbols and operating with them which can become problematic if manipulatives are used in a disconnected manner from other mathematical learning. Given these concerns about both digital and concrete manipulatives, we will argue later in the article that it is not immediately possible to clarify an app as good or bad but only to consider it in relation to the broader pedagogical goals it is meant to support. Furthermore, concerning concrete and digital manipulatives, Ladel (2018) shows different ways to combine them with one special kind of combination being a "duo of artifacts" (SouryLavergne, 2016), where concrete and digital artifacts are used side-by-side to enrich the learning of a specific concept or skill.

Moyer, Bolyard, and Spikell (2002) initially defined a virtual manipulative as "an interactive, Web-based visual representation of a dynamic object that presents opportunities for constructing mathematical knowledge" (p. 373). However, given the recent developments in modes of representation, Moyer-Packenham and Bolyard (2016) now suggest a new definition of a virtual manipulative as "an interactive, technology-enabled visual representation of a dynamic mathematical object, including all of the programmable features that allow it to be manipulated, that presents opportunities for constructing mathematical knowledge" (p. 13). At their core, virtual manipulatives provide students with opportunities to interweave pictorial and symbolic representations, with the actions that they perform on them, to emphasize the underlying mathematical concepts. Ensuring that these connections can be made has clear implications in using ACAT to design and / or evaluate apps.

The positive outcomes attributed to the use of concrete manipulatives (See Carbonneau, Marley and Selig 2013) are mirrored in findings from research into digital manipulatives. Clements and 
Battista (1992) found that student ideas about shapes were more precise and mathematically robust

after using computer-based Logo software. Özel (2012) reported on affective gains following the use of virtual manipulatives and noted that immediate feedback enhanced student self-efficacy. In addition, Özel reported that the use of virtual manipulatives was identified with reducing the time it takes to learn the affordances of a related concrete manipulative and also with enhancing student enjoyment, attitude and interest in mathematics; an important consideration given the often negative attitudes towards mathematics exhibited by young learners (Jorgensen and Larkin 2017).

It is therefore largely uncontested that virtual manipulatives play a special role in mathematics education. Although these findings predate the relatively recent introduction of iPad apps, the added interactivity of iPads will likely improve student outcomes, with the proviso that apps are designed to the same quality as the virtual manipulatives investigated in the previous studies. In summary, although it is important to note that external representations of any form can never exactly represent a student's internalization of a concept; we agree with Zbiek, Heid, Blume and Dick (2007) when they suggest that manipulatives "are useful as visible phenomena that can be shared and discussed with others (e.g. other learners or the teacher and thus help teachers understand conceptual difficulties that students face)" (p.1173).

\section{Evaluating Apps}

In the research literature there are three major modes for investigating mathematics apps: large-scale reviews of apps; targeted reviews of small samples of preselected apps; and designing purpose-built apps. We address each of these modes in turn.

Large-scale reviews of apps are prevalent and mainly involve reviews of iPad apps, as they are the tablets of choice in most elementary / primary schools (for a review of Android apps see Papadakis, Kalogiannakis and Zaranis 2018). Highfield and Goodwin (2013), for example, evaluated apps in relation to age appropriateness, curriculum content and an initial classification of "constructivemanipulable" and "manipulable-instructive". Powell (2014) suggested that educators begin with "an app search using the standard iTunes categories: 'Best New Apps,' 'Top Free Apps,' or 'Top Paid Apps'. Whilst reviews such as these provide some information for teachers, they lack either methodological rigour or a theoretical underpinning (Baccaglini-Frank and Maracci 2015). More robust reviews of apps have used: Gee's Design Principles (Larkin 2015); Dick's (2008) Three Fidelities - Pedagogical, Mathematical and Cognitive (Larkin 2016); Cluster Analysis (Larkin and Milford 2018; 2018b) or usability frameworks (Namukasa et al 2016; Papadakis et al. 2018) to provide teachers with a more robust selection of appropriate apps for use in classrooms. A restriction in the approaches noted here is the sheer number of apps that need to be reviewed - as at May 2018 there were over 270000 educational apps at the App Store (PocketGamer.Biz August 2018). In addition, both the Appstore and Google Play are in a constant state of flux with apps being renamed, removed or recategorised (Larkin 2013).

A second approach to evaluating apps involves researchers deliberately selecting a particular app, or a small set of apps, for analysis. For example, the app [Fingu] was used to better understand how young children master part-whole relationships in numbers up to ten (Baccaglini-Frank and 
Maracci 2015; Holgersson et al. 2016); two apps [Motion Math Zoom] and [Dragon Box] were used in

the work of Tucker (2016) to understand student interaction with apps; and a larger set of 18 apps were chosen by Moyer-Packenham et al. (2016) in an analysis of how these apps aided student development. Of interest in this last study was the finding that although the apps aided student development, the level of development was varied, highlighting the difficulty in making broad educational claims regarding the use of mathematics apps. A restriction of this second type of app research is that some process of quality selection has already occurred before the more targeted investigation is discussed. This is of limited use for teachers given the glut of apps noted earlier and thus teachers may be unsure as to which apps deserve the closer evaluation that this research method entails.

The third approach in investigating quality apps involves mathematics educators designing and building apps targeting predetermined mathematics concepts. These examples are of particular relevance for us in this article as they are underpinned by specific theories of learning. For example, the app [TouchCounts], was created to support haptic learning of early number and supported later research investigating the role of rhythm in early counting (Sinclair, Chorney and Rodney 2016). This work builds upon the notion of "finger gnosis" where direct and tactile engagement with the app fostered cardinality (Sinclair and Pimm 2015). Ladel and Kortenkamp (2013; 2016) investigated the usefulness of their app [Place Value Chart] in supporting a range of place value concepts. The app is a virtual place value chart that can be filled with counters, which can be moved between columns, to demonstrate place value concepts. Various options are available within the app including the opportunity to add or remove base ten places, (including decimal bases), change the base, or automatically group and ungroup places - e.g. a counter in the 100s column becomes ten counters when moved to the tens or one hundred counters when moved to the ones. Apps such as [TouchCounts] and [Place Value Chart] are very useful for developing number concepts. The question remains whether the theoretical underpinnings of these specific, pedagogically designed, number apps are applicable to a broader range of apps, in this instance, two geometry apps [Pattern Shapes] and [Click the Cube]. This article now attempts to address this issue of transferability in relation to ACAT, the theory underpinning the design of the app [Place Value Chart].

\section{Artifact Centric Activity Theory (ACAT) Framework}

The conceptual underpinnings of [Place Value Chart] are based in socio-cultural theory suggesting that subjects (in this case young children) have needs (in this case learning about place value) and, in order to meet those needs, carry out activities (in this case using the app). Ladel and Kortenkamp (2013) devised ACAT, a modification of Engeström's (1987) Activity System, to closely investigate the pivotal role of tools (apps) in the socio-cultural activity of learning mathematics. As ACAT is used here as a research tool to investigate the value of apps, it is necessary to initially understand Activity Theory and then outline the ontological, epistemological, and methodological contribution of ACAT.

ACAT has its genesis in Activity Theory, a body of theorising and research initiated in the 1920's and 1930's by Lev Vygotsky and Alexie Leontiev, the founders of the cultural-historical school of Russian psychology (Engeström, Miettinen and Punamaki 1999). Activity theory is an approach that aims to assist researchers to understand individual human beings in their natural, daily circumstances. 
This understanding occurs through an analysis of the genesis, structure, and processes of their activities. Human activity is always oriented to the achievement of goals and motives (Nardi 1996) and in this sense activity implies an action done in order to transform some object (Engeström 1999). Activity is understood as a purposeful interaction of the subject with the world, a process in which mutual transformations between subject and object are accomplished (Kaptelinin and Nardi 2006). Engeström reconceptualized the primary Activity Theory heuristic from the initial subject-tools-object triangle into a six element model (Figure 1) that has become an analytical tool used in a wide range of educational and Human Computer Interaction (HCI) research (e.g. Kaptelinin 1996; Ladel and Kortenkamp 2016; Larkin 2011).

Fig. 1 An Activity System (Engeström 1987 p.37)

Minimum elements of this system include the object, subject, mediating artifacts (signs and tools), rules, community, and division of labour. Engeström's (1987) framework provides a schematic for the structure of activity, which can then be used to examine how the various socio-cultural elements impact upon individuals within the system. In this schema, the most basic relations are a subject (person) oriented to accomplishing some object (outward goal, concrete purpose, or objectified motive) using a historically constructed tool. By way of a mathematical example, in [Pattern Shapes] the child (subject) is oriented towards completing the filling of an outline encouraging concept development of area and tessellations (object), using a range of 2D shapes via a drag and drop action on the iPad (tool). Although the designer has some object in mind in creating the app, once the app is built, it is up to the user to determine his or her own mathematical object (within the design parameters of the app). To this initial triangular relationship, community is added, generating two more links; a subject relates to the community via rules (norms, conventions); and the community relates to the object via division of labour.

Contradictions exist when external influences change elements of activities causing imbalances between them, and resolving these contradictions is the primary mechanism for development. Consequently, Activity Systems are almost always in flux as they work through contradictions, which manifest themselves as problems, ruptures, breakdowns, or clashes (Scanlon and Issroff 2005). Although tool use is one of six elements within an Activity System, in our research on iPad apps it was 
felt that a reorganization of the Activity System was necessary to more clearly demonstrate the pivotal role of tool use in goal oriented behaviour using digital tools. ACAT can therefore be positioned as a further development of Activity Theory and Activity Systems.

ACAT is thus a theoretical and methodological tool that helps educators and designers to initially understand, and then later to structure, the complex network of relationships in the interacting Activity System of teaching and learning with digital tools. The causal network includes five components (subject, artifact, object, rules, group) that mutually effect, and are affected by, each other (Figure 2).

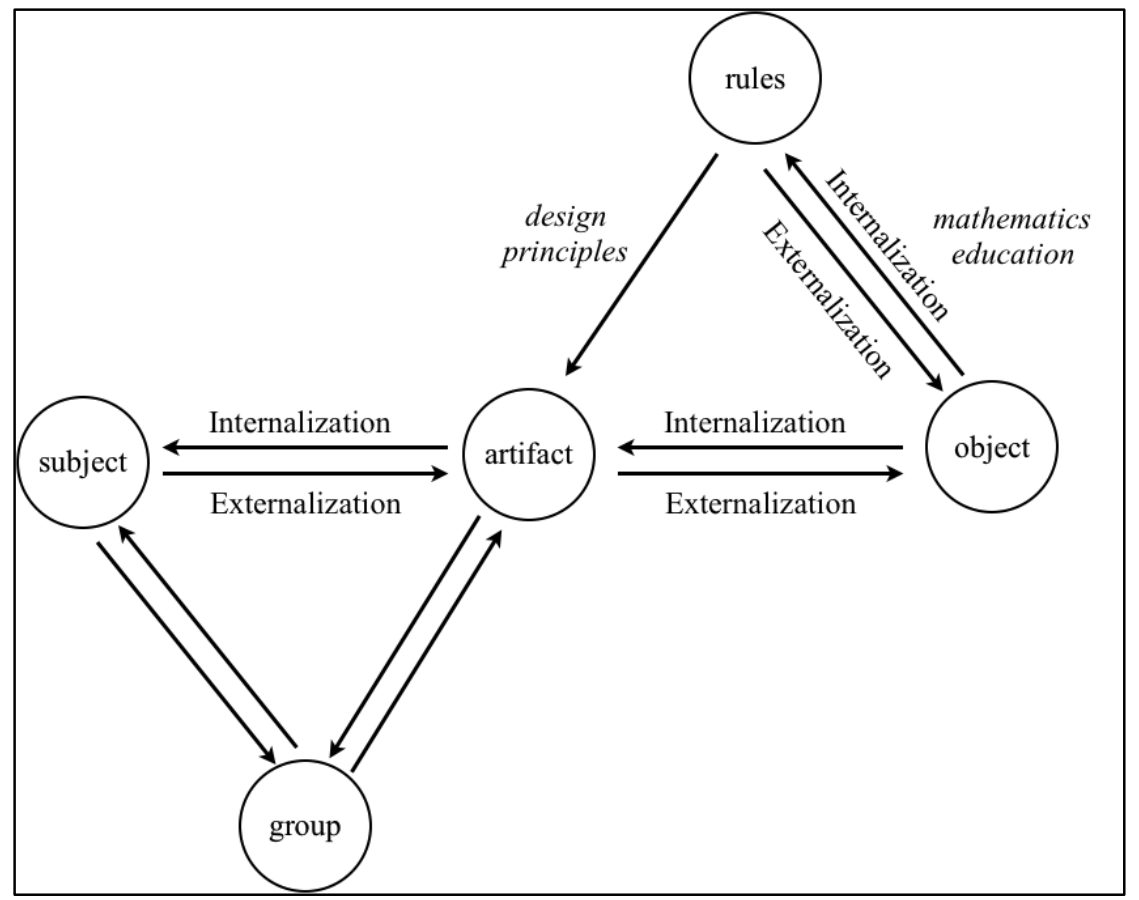

Fig. 2 The ACAT Model (Ladel and Kortenkamp 2011)

The Activity System in ACAT consists of three main sub-structures: the main axis (subject-artifactobject); the upper right triangle (artifact-object-rules); and the lower left triangle (artifact-subjectgroup).

In the main axis, the processes of internalization and externalization take place. The activity between subject and object is mediated through an artifact - see Vygotsky's "Instrumental Act" (1980 p.311). This artifact is a critical consideration within ACAT. At this point, and taking into account any rules built into the artifact, the subject is able to exercise agency in how they interact with the artifact. For example, in [Pattern Shapes] the subject can decide the type of activity they wish to engage with, whether to use a scaffold (a grid), or whether to create a new design or use one of a range of designs built into the app. The upper right triangle concerns the design of the artifact. Here the app designer makes decisions regarding the aesthetic appeal of the app, as well as considering how the construction of the app will motivate, engage or challenge users. In addition to aesthetics, it is here that an app designer would make decisions about the type and frequency of feedback that children will receive whilst using the app. This is no small matter, and an important contribution of this sub-component of ACAT, as inappropriate feedback is determinantal for learning. For example, in [Math Exercise! 
KizzMath5] an incorrect answer prompts one of the app characters to vomit. We discuss feedback about with reference to different disciplines such as psychology, mathematics education, or media didactics. The artifact represents the object in an accurate way and, concurrently, the object is encoded in the artifact that is limited to the object's properties (Ladel and Kortenkamp 2013). The lower left triangle is related to the use of artifacts in classroom situations. Although Division of Labour is not explicit in the ACAT model, it is present in the interactions between the artifact, the subject, and the group.

Thus far, ACAT has primarily been used as a conceptual frame directing the design of new apps, in particular the [Place Value Chart] app; however, other authors have begun to evaluate apps using the ACAT model (see Lommatsch, Tucker, Moyer-Packenham and Symanzik 2018; Tucker 2017). What is required now is a determination as to whether ACAT can contribute to understanding how existing apps might be usefully deployed in classrooms. It is essential here to indicate that we do not envisage using ACAT to categorize an app as "good" or "bad" as there is, within reason no a priori good or bad app. It is only possible to argue, with the help of the ACAT model, whether an app is useful to support certain learning or not. As an example of using ACAT for this purpose, we provide, as a case study, an example of the review of the app [Pattern Shapes], utilizing a review guide built upon ACAT principles (See Appendix One). We report in full the creation of the review guide in another publication (Etzold, Kortenkamp and Ladel 2018); however, for the purposes of this article, we only provide a brief summary of the process behind the creation of the review guide and then use the guide to demonstrate how ACAT can assist classroom teachers in evaluating whether (and then perhaps how and when) a mathematics app is beneficial to teaching and learning in their classroom.

As described above, the ACAT model has been created by re-purposing the model of Engeström, to enable a closer investigation of the effects caused by the use of digital artifacts as a mediating element between a subject and an object. The horizontal subject-artifact-object axis needs to be described in order to understand the internalization and externalization processes that occur when using the artifact. This was also the conceptual spine underpinning the creation of the ACAT review guide described below. As every activity can only be described by specifying how the various components of ACAT are connected, we decided to formulate some fundamental questions to specify the object, the artefact, the subject, the rules and the group in specific contexts - the main axis and also the upper right and lower left triangles. When we describe the questions below, we depict the context (gray) and the component in question (circled) in small thumbnail figures. A clean version of the complete ACAT review guide is also attached as Appendix 1 and is also available at http://dlgs.unipotsdam.de/oer

\section{A Review Guide for Apps}

The following review guide is organized into a sequence of five steps to be followed in the prescribed order. The entire review is guided by the mathematical content of the app, in ACAT terms, its mathematical object, as well as a developing understanding of how students might be expected to work with the app. As a consequence, we ascertain whether or not the app is suitable for supporting the teaching and learning processes of this specific content. Specific classroom situations where the app 
can be used productively are proposed. This is a critical point often overlooked in more global reviews completely unsuitable for another e.g. initial area concept. Finally, many existing app reviews consider the student users as largely homogenous. Of course, as teachers, we recognise that students are individuals with a range of mathematical competencies. ACAT, with its focus on individual subjects, acknowledges this diversity; indeed, this aspect is noted unprompted within the student review of [Click the Cube] later in this article.

This review guide also quickly identifies, early in the process, apps that are unsuitable, prompting a decision not to utilize the app and thus saving teachers from expending precious time in continuing the review when it is already apparent at an early stage that the app will not be useful. We also provide, for each step, a list of the possible data sources to aid decision-making and also discuss the relationships between key questions and the ACAT model. As mentioned earlier, we will illustrate each step via the review of [Pattern Shapes] using the ACAT review guide. Each step of the guide includes, for the teacher, a short description of what to do, possible sources to assist them, the example of using that step of the guide on [Pattern Shapes], and a brief theoretical background. Appendix 1 provides the clean version of the guide, so that teachers can copy and use it to review an app they are considering for their classrooms. Although the amount of time taken to complete the review of an app is somewhat arbitrary, we anticipate that 30-45 minutes would be a reasonable prediction. The independent evaluator (student teacher) in our example took over an hour to complete her review; however, her review is likely more thorough than would be undertaken by more experienced classroom teachers. The guide was created to be used by classroom teachers without specialized theoretical knowledge of ACAT and, based on our early work with teachers, we are confident that the guide will be a useful addition to their repertoire in selecting appropriate apps for the students they teach. Part of our next research project is to more broadly test this supposition with a larger group of teachers.

\section{Step 1: What is the mathematical object of the app?}

Firstly, the guide helps reviewers to identify the mathematical object i.e. which concept, content or mathematics process is targeted by the app. It is important to note that each app can address one or several mathematical objects. In the case of several objects, separate reviews for each object are necessary as each object will emphasize different learning facets and will therefore vary in efficacy across this range of facets.

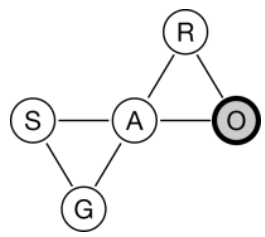

\section{Possible Sources}

- The app's title and its official description at iTunes or Google Play

- Additional material provided (e.g. downloadable worksheets)

- External references (e.g. recommendations by peers who have used the app)

- Trials of the app

\section{Background}

A central principle of activity theory is object orientation. As actions only exist (or at least can only be recognized) in relation to a specific object, activities are therefore directed towards the attainment of an object. Consequently, actions of students within an app can only be understood if the (mathematical) object of their actions is known. For example, when using a counting app, the mathematical object 
might be children understanding how numerical symbols represent the objects they have been grouping together on the screen. Although it is not possible (and possibly not desirable to do so) to guarantee that teachers will always identify the same mathematical object, the guide is helpful in directing teachers to reflect on their pedagogical purpose for using the app.

\section{Example [Pattern Shapes]:}

According to the App Store and the web site of the publisher (The Math Learning Center, https://www.mathlearningcenter.org/resources/apps/pattern-shapes [Pattern Shapes] is useful for the manipulation of various shapes, investigating symmetry, and demonstrating fractions as parts of a whole.

As these are separate mathematical objects, in this example review, we will focus only on the manipulation of basic shapes, as offered in the app (equilateral triangles, right-angled isosceles triangles, squares, rhombi, trapezoids, other rhombi, and hexagons) and shapes created by combining rotated and translated versions of them as the mathematical object. By way of a brief example, children can use the combining feature on the app to discover that two equilateral triangles cannot be combined to create a square. In this sense, by dragging, dropping, and rotating, they are developing an understanding of a square as a mathematical object. It might be considered here that the static, visual register, and also the prototypical representation of shapes are a negative aspect of the app. And this may be so, if the mathematical object of the app was to be dynamic or to challenge this misconception. However, on occasion, being static is a positive. We initially thought this was a problem with [Pattern Shapes]. We then came to appreciate that, as the shapes are later used for area, then it is important that the objects don't change size. In this app, the mathematical object is not about size, nor is it about modifying triangles to learn about the nature of triangles. This reminds us that it is important to identify the mathematical object as, although there are a range of things that might improve an app, they might detract / distract a teacher from identifying the specific mathematical object that a teacher is focusing on. Due to the deliberate focus on specific mathematics objects in the review guide, two subsequent separate reviews would be required to assess the usefulness of the app in teaching symmetry or fraction understanding.

Step 2: How do students interact with the mathematical object, mediated by the app? This section of the review guide helps to document what kind of interaction with the mathematical object the app offers to the students. For this, it is necessary to look at the separate interactions between subject and artifact as well as between artifact and object. In examining these interactions we can ask: What actions does the app support? How does the

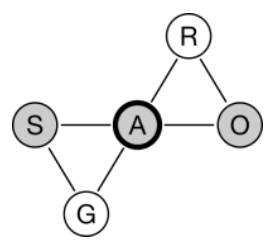
app represent the mathematical object? How does the object influence the "behaviour" of the app? What can students experience through the above?

Possible Sources

- Individual systematic testing of the app

Background

When designing an app, formulating the rules for user interaction would occur at this stage in the ACAT design process. As we are analyzing an existing app we immediately examine user interaction. 
A core component of interest in Activity Theory, and thus ACAT, is the process of Internalization

and Externalization. External actions of the subject, such as pinch-to-zoom gestures to scale a city map represent internal actions, in this case dilations, that in turn are representations of student understanding. In a similar way, external actions can affect representations on an app, e.g. the way a user's fingers are positioned can affect the way numbers are represented in a counting app. In order to understand this user interaction more fully, and to refer more concisely to the mathematical object, it is useful to sub-divide this process between subject and object at their respective interactions with the artifact (Ladel and Kortenkamp 2014a).

The guiding questions thus follow back and forth between subject, artifact, object:

$\mathrm{S} \rightarrow \mathrm{A}:$ What actions does the app support?

$\mathrm{A} \rightarrow \mathrm{O}:$ How does the app represent the mathematical object?

$\mathrm{O} \rightarrow \mathrm{A}$ : How does the object influence the "behaviour" of the app?

$\mathrm{A} \rightarrow \mathrm{S}:$ What can students experience through the above?

\section{Example [Pattern Shapes]:}

Shapes are created in the app by selecting from a palette, using either a "click" or a "drag" motion, and then placing the shapes onto the workspace. The shapes can be moved with the finger by tapping on them and they can also be rotated by any degree of turn. However, a design feature of the app is that the shapes "snap" either forwards or backwards in increments of $5^{\circ}$. This is an important design decision (rule) as it makes the later tiling and combinations of shapes more accessible to the students thus impacting of the Subject-Artefact interaction and the Artefact-Object behaviour.

A possible point of confusion for students is that the icon for rotation might be considered as an icon indicating only a clockwise turn. However, it could also be interpreted as a more representational symbol for turning. In any event, students will soon experience that the shapes can be rotated in both clockwise and anticlockwise directions. Likewise, it might be a design flaw in positioning the rotation icon external to the shape being rotated as it might indicate an external rather than internal point of rotation. Again, students will soon notice that the shapes are rotating around a centre rather than external point that in turn can be seen as a handle.. Several shapes can be combined into a group that can then be moved or rotated. Using a "throwing" motion, pieces fit together nicely and the action is intuitively correct. Outlines can be chosen from a library or easily created from an existing pattern. It is possible to duplicate a shape (or a group of shapes) or to scale them. Scaling is restricted to two discrete scaling factors. A rectangular or triangular grid can be switched on or off and this supports the "snapping" as well; however, tiles do not "snap to the grid" during movements.

\section{Step 3: How does the interaction develop?}

At this stage the guide helps us to structure the possible interactions, between subject and artifact, by categorizing them into activities, actions, and operations (Leontiev, 1981):

- Activities are superordinate interactions directed by the subject's motives, e.g. reading a city map to determine direction of travel;

- Actions are targeted, individual interactions, e.g. changing a map's scale to get a more detail view of a certain section of a map; and 
- Operations are internalized interactions that do not need further cogitation and can be governed by instrumental constraints, e.g. the actual execution of pinch-to-zoom gesture to scale or of the drag gesture to move the map.

The guide helps a reviewer to elaborate upon how this categorization changes while using the app as actions can become operations during the learning process and allow for the creation of new actions in turn e.g. when using a scaling type app, learning to pinch-to-zoom is an action. As this action becomes internalized, it functions as an operation as the user can now attend to the output of the operation, consequently the user then can focus attention on the new actions available. A more detailed example of this is provided below when we examine [Pattern Shapes].

Possible Sources

- Discussion of hypothetical scenarios

- Empirical tests

Background

At this point in the review process a specific view on the hierarchy of activities, actions and operations, as another principle of Activity Theory, is appropriate. At the same time, conclusions about possible developments of students' learning can be drawn. A successful learning process is characterized by actions becoming operations in order to enable more complex actions. Step 3 in the guide provides the reviewer with a second appropriate juncture at which to quit the review. If, at this stage, the reviewer feels that the review indicates that the app is not supporting any development of the investigated object, then the review can be stopped, as proceeding further in unnecessary as it has already been determined that the app is inappropriate for this particular mathematics object. During the research process we used the review guide on a number of apps; some of which were determined as inappropriate to continue to Steps 4 and 5. As the sampling was nonsystematic, we won't criticize these apps publicly. In our review of [Pattern Shapes] we identified worthwhile learning processes and thus we continue to Step 4 and 5 of the review guide.

\section{Example [Pattern Shapes]:}

Initially, some interactions of the app can be categorized as follows:

- Activity: Create combined shapes from basic shapes in order to match a given outline.

- Actions: Add shapes, move shapes and rotate them.

- Operations: Drag gestures to add or move and rotate gestures with two fingers to rotate shapes in increments of $5^{\circ}$.

Students create their own shapes by combining pre-existing shapes using either pre-loaded outlines or with outlines of their own. After working with the app, adding a shape at a specific place, or "glueing" it to another shape, becomes an operation itself, supported through the instrumental constraint of snapping. This increases the number of available basic shapes for the students, allowing them to create even more complex outlines and perform more sophisticated actions. These interactions are also supported by the option, within the app, of the subject being able to make multi-selections of shapes. 
Step 4: Is the app suitable for teaching and learning the mathematical object? At this step we compare the use of the app for the specific mathematical object, as uncovered in the guide, with knowledge from mathematics specific pedagogy, the discipline of mathematics, and psychology regarding the teaching and learning of the mathematics object in question. In other words, do the interactions identified and analyzed in Steps 2 and 3 support the desired ideas, experiences, conceptions, and competencies, as

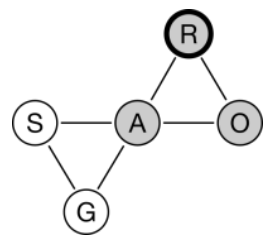
normally required by quality mathematics education? In addition, is the technological design suitable for learning according to theories of high quality HCI design?

\section{Possible sources}

- Syntheses of the discussion above

- Scientific background literature and references

Background

The design of an app is guided by rules in the ACAT model, which in turn are guided by knowledge from mathematics education and HCI design. This ensures that the app is indeed supporting student learning of targeted mathematical concepts or skills. This is a potential point of difficulty for some teachers as for some apps, that are broad in scope, might be useful for a range of concepts and thus may confuse teachers in determining the specific mathematical object they wish students to learn about. The fundamental point of the guide is to scaffold teachers in determining the mathematical object of the app, and also the pedagogical implications of using the app, when they are reviewing an app prior to its potential use in their classroom. Thus, a teacher might make the decision to use a specific app for developing understanding of how certain shapes are appropriate for determining area and a second app such as Cinderella/Cabri for developing synthetic geometry understanding. The guide therefore encourages teachers to be precise in their selection of an app for a specific purpose rather than the temptation to use a multi-purpose app that in name at least could develop many concepts but may in fact not be as pedagogically appropriate in helping children learn a concept as an app with a very specific mathematical object in mind.

\section{Example [Pattern Shapes]:}

Based on the information gathered at Steps 1, 2 and 3 of the guide, and comparing this to how mathematics education normally deals with these concepts and mathematics processes, we can conclude that [Pattern Shapes] is suitable for teaching and learning about properties of 2D shapes. For example, the mosaic puzzle of van Hiele (1999) uses a similar restriction in angles to the one the app provides. The Van Hiele example is provided as research material that is provided on the [Pattern Shapes] website. However, we are not suggesting that the app must be used only to develop geometry understanding using the Van Hiele theory as a pedagogical approach. Later in Step 5 we develop the pedagogical knowledge required to use the apps in classrooms.

\section{Step 5: How can the app be used in classroom instruction?}

Finally, at this stage we illustrate how the app might be used in the classroom. The following questions can serve as a guide.

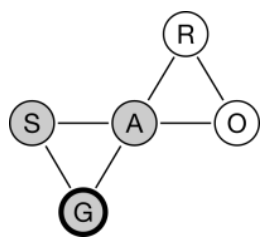


- Can the app be used for individual, partner or small group work or is it limited to only one of these types of social interaction?

- How can classroom discussions / collaborations / and interactions be fostered through activity with the app, either directly or indirectly?

- What are possible provocations or tasks that a teacher can provide students?

- Which kinds of differentiation, and which levels of difficulty, are possible?

- Is it an app for instructive (drill and practice) activities, or is it discovery based and designed to introduce students to new content or to construct new ideas?

- Which requirements and competences are necessary to use the app?

Possible sources

- Additional materials for teachers

- Trials with students

- Results from experimental studies by other researchers

- Imagination

\section{Background}

Within both Activity Theory and ACAT, learning is never understandable as a pure individual activity of a student. It must always be seen in a social and corporate context where learning is common work. As noted by Giest and Lompscher (2004), in the classroom there is always a "pädagogisches Gesamtsubjekt" such that the learning activities always occur in the contexts of interaction, communication or cooperation, including relationships between learners, teachers, and other participants.

\section{Example [Pattern Shapes]:}

When using the app, the following provocations can be presented to stimulate the students:

- Students use the tiles to build their own pattern or design and then partners are to recreate the initial pattern or design;

- Students are required to fill a particular outline; and

- Students investigate whether transforming shapes (rotation, reflection etc.) changes the structure of the shape.

Specific questions such as the following can be asked:

- How many triangles do you need to build your shape / design?

- Can you use rhombi instead to create the same shape / design? If so, do you need more or less shapes to do so?

- What is the most efficient way to build your shape / design?

- Can you combine equilateral triangles to create squares? Use a protractor to prove your claim.

Although we have created these questions (in the role of teacher reviewer), we are of the opinion that questions of this type would be posed by competent mathematics educators. As more teachers use the 
guide, we envisage that they might be shared via social media (Facebook, Twitter, Pinterest etc.) and could be a prompt for teachers to form informal Communities of Practice.

\section{A Vignette}

What we have presented thus far is our evaluation of the app [Pattern Shapes] using the ACAT review guide. We did this for two reasons, firstly to demonstrate the use of the guide and secondly, to determine whether [Pattern Shapes] is an appropriate app for primary classrooms (in our view it is). We noted earlier that one of the limitations of much of the research concerning app design, and the use of review guides, checklists, inventories and the like in evaluating apps, is that they are designed by the authors of the research or used by authors on apps they have created. At this stage it would be accurate to note that thus far we have failed to escape this conundrum.

As an initial step in what hopefully will become a widely used evaluation tool for apps, we invited Sarah Stein, a German Master of Education student, to use the ACAT review guide to evaluate a second geometry app [Click the Cube]. It is appropriate to provide some background information about Sarah. Sarah was a conscientious student who was fully engaged with the mathematics course and indicated an interest in reviewing some mathematics apps. The review of the app was not part of the course and thus there are no ethical concerns about her review. A number of students, and also some teachers, wrote reviews of apps using ACAT which will be used in future publications. This review was chosen as it demonstrated the full scope of the review guide. Sarah's full review is attached as Appendix 2. It should be noted that the review of [Click the Cube] was completed prior to its use with a class. This is an inherent design feature of the guide as it is intended to filter apps prior to teachers wasting valuable learning time in the use of an inappropriate app. We didn't invite any students or teachers to review [Pattern Shapes] for two reasons. Firstly, we wanted additional examples of the guide in action in relation to a range of apps and we already reviewed [Pattern Shapes] chosen randomly from a set of ten apps reviewed in other publications (Larkin, 2015, 2016) and using different measures. Secondly, this article is not reporting on a confirmatory study in relation to consistency between two reviews of the same app. This reflects the intent of the guide to be a individual review of an app as, when teachers are reviewing apps, they won't necessarily review them for the same mathematics object.

We now discuss: the experience of the student using the guide; how her experiences of using the guide compared with our review experiences; and the implications these combined experiences have for the further development and use of the review guide. Sarah commences the review by listing general information about the app (Lines (L.) 3-19) and clearly focusses on the content and not on technical details. This approach is in contrast to many other review guides that commence by looking at overall app design, and thus, in our view, Sarah's decision sets the stage for a review that tries to capture the contribution to (mathematics) learning of an app rather than its technical or instrumental qualities. After recording this information - without judging it yet - she identifies concisely the mathematical object(s) of the app (L. 21-23): "The mathematical objects of the app are cubes and their 
nets. The app focuses on the relation between 2D and 3D representations of cubes and should enable students to develop better spatial abilities."

In Step 2 she now describes precisely the interactions, leading to one and a half pages of description (L. 25-82) highlighting some of the interactions she found: "The user can rotate and scale the net and use a slider to fold or unfold it gradually. The first operation, rotation, is done through pan gestures. It is not a requirement to start the gesture on the net as it is possible to start anywhere in the right area, allowing the student to see the full net in rotation. Through this gesture the user can see the object from all perspectives. With a pinch-to-zoom gesture the user can change the scale of the net, to enlarge or shrink it on the screen." (L.31-36) The text is indeed concerned with the interaction only, and she is describing, without judging, its potential implementation. She does not explicitly mention internalization or externalization processes; nonetheless, her descriptions clearly indicate an understanding of the processes. We can see that she does not require detailed knowledge regarding the theories underpinning either ACAT or internalization/externalization but yet still captures the important concepts of both. It is possible to identify separate descriptions of processes as suggested in the review guide:

- $\quad \mathrm{S} \rightarrow$ A (e.g., L. 31-33, describing rotate, scale, fold and unfold of the net, see above)

- $\quad \mathrm{A} \rightarrow \mathrm{O}$ (e.g., L. 44-46: "The net of the cube is coloured in white on one side and grey on the other. When folded, the grey side is on the inside and the white side is on the outside. Thus, a fully folded cube will appear white." - the artefact is representing the object specifically and encodes the inside and outside of the $3 \mathrm{D}$ object)

- $\quad \mathrm{O} \rightarrow$ A (e.g., L. 60-61: "The new squares are glued automatically to the existing net if they are brought into the vicinity of an edge." - the mathematical property of connectedness of nets is externalized through the artefact)

- A $\rightarrow$ S (e.g., L. 61-64: "To check the current net for correctness the user presses the "Check" button. This will determine whether a correct net has been formed and at the same time the folding process will be demonstrated with an animation in the right area of the screen." - on demand, students can experience the mathematical object as represented by the artefact). This is an important observation by Sarah and one likely to be noticed by most educators. The feedback provided by this app (that was designed by a mathematics educator) is not of the vacuous nature provided in an earlier example, and is not simply a mechanism for keeping the children playing, but rather provides a targeted scaffold to assist children in understanding the underlying mathematics - in this case the notion of nets.

In Step 3 Sarah begins to connect concepts from mathematics education, with the development of interactions, by referring to "mental geometry" (L. 84-92). Just as mental arithmetic can be described as solving computational tasks without writing algorithms, mental geometry can be described as solving geometric tasks by thought processes alone. Both mental arithmetic and mental geometry are common components of German K-4 mathematics teaching. She uses this reference to provide a structure to the development of interactions in the app. Sarah uses her specific knowledge in mathematics education when describing the development of interaction in (L. 93-107) and already 
considers the app to be helpful for developing the competency of mental geometry: "The app stimulates mental operations in various ways, so I consider it as a tool that helps students to acquire the competency of doing mental geometry" (L. 105-107). The guide does not require this, as the description of interaction can be done without any explicit theoretical connection to mathematics education. We can also see that the review guide provokes a deeper thinking about the app that already results in suggestions for improvements from Sarah (L. 108-124): "prevent overlapping faces", "animations for misplaced squares", "tap-tap gestures for colouring", "increased contrast".

In Step 4 we can observe that Sarah judges the app based on how it could or should be used in the classroom (L. 126-130), and considers in particular, the prerequisites for using it effectively (L. 130-131). A common problem in app reviews is that they do not consider the context where the app is meant to be used. Sarah lists several contexts she can imagine where the app could be used successfully to improve student learning outcomes. She recognizes the potential of the app and opines her view on teaching cube nets (L. 137-138, "Using the app also opens new ways to work with cube nets and should be seen as a supplement to cut-out nets and crafting cubes from these.”), placing particular emphasis on the affordances of digital media (L. 138-139, "The app cannot replace the haptic experience, but offers training that could not be done with paper or cardboard material or images alone"). Here she also cites academic literature, which is not expected from a teacher, but as she is a masters' student in her final year she is accustomed to thinking and writing academically.

Sarah suggests (L. 141-148) a learning scenario for differentiated learning, which is connecting her pedagogy with mathematics education theory and the app. It is important to note here that we are not making global claims as to the veracity of ACAT in suggesting modifications for all diverse learners, for all apps; however, initial reviews are encouraging that this is a feature of ACAT that might be beneficial to classroom mathematics teachers in catering for the diversity of learning in their classrooms. This suggested learning scenario anticipates Step 5, where Sarah concludes with classroom examples (L. 153-159: "several options", “individual work", "repeated several times", "learning stations", "talk about and compare", "saving time and materials after [...] creating boxes"). Sarah also outlines difficulties that might occur when using the app in the classroom (L. 160-167: "it will be difficult for the teacher to address the problems of each individual that result from using the app", ", it is not discernible whether the student solved 20 tasks with help or only 10 tasks without help"). This critique is helpful and necessary, and the ACAT review guide encourages users to complete such critiques. However, it is good to perform this critique late in the review process as potential positive uses for the app might otherwise be missed. As a bonus, Sarah also adds further notes concerning the mathematics, pedagogy, design, and technology that can be helpful for developers of the app and demonstrates her deep involvement in the analysis (L. 170-189, suggesting cuboid nets, better movability of the free square, an option for accessibility, another reward scheme, and adaption of the scoring scheme for mental geometry tasks). It is a consideration that Sarah may have noticed many of the things she did without the guide. This is true; however, it is not possible to know what Sarah would have noticed about the app without the use of the guide. We argue that the value add of the review guide is that it is makes explicit the types of questions that teachers might ask when reviewing apps. 
Putting the previous concerns aside, we are of the view that Sarah's review of [Click the Cube] indicates the usefulness of both the ACAT model, and the ACAT review guide, for classroom teachers.

\section{Conclusion}

Ladel and Kortenkamp, in a number of earlier research publications $(2011 ; 2012 ; 2013 ; 2014 ; 2016)$, have succinctly explained the theoretical and methodological underpinnings of ACAT and articulated how these underpinnings guided the creation of [Place Value Chart]. The logical extension of this earlier body of work is to determine the value of ACAT beyond this one app. This article is the first step in this further development and here our aim was to critique the usefulness of ACAT in a range of scenarios beyond the earlier research. These scenarios include: an expansion of the original design team (Larkin and Etzold); a new mathematics content area (geometry with its heavier demand on exactness of external representation and mental geometry); an app not designed by Ladel and Kortenkamp (and perhaps not even a mathematics educator); the creation of a review guide; and finally, the use of the review guide by a student teacher to evaluate a second app [Click the Cube].

Although always confident that the theory and methodology of ACAT was on firm conceptual and pedagogical grounds, we can now begin to support this confidence with a broader range of evidence. Firstly, new members of the research team were able to quickly understand the ACAT model and use it to evaluate a range of geometry apps initially reviewed by Larkin (2016). We will report on this evaluation in upcoming publications. Secondly, the central innovation of ACAT, i.e. the focus on internalization and externalization along the horizontal axis of subject-artifact-object, was critical in evaluating the quality of [Pattern Shapes] as an app requiring high-level representations of shapes to aid the student in understanding the mathematical object. Thirdly, as the authors are all mathematics educators, it could be argued that the ACAT model is sufficient for us to understand the underlying theory and methodology and thus be well positioned to use the model to evaluate apps; however, such an assumption may not be valid for student teachers, beginning teachers, or even experienced classroom practitioners. As our research showed, a Master of Education student, who had no role in the initial design of either ACAT, or the ACAT review guide, was able to use the guide to evaluate [Click the Cube]. Importantly, but often absent in many review guides that focus instead on levels of fun or engagement or interaction, she was able to identify precisely which mathematics concepts and processes would likely be enhanced via the use of [Click the Cube].

Although we argue that the research presented here is a significant further step in confirming the value of both the ACAT model and the ACAT review guide; this optimism is tempered by a number of considerations. Firstly, the research to date is small in scope and only involves the evaluation of three apps; namely [Place Value Chart], [Pattern Shapes] and [Click the Cube]. Secondly, this research has been largely conducted by the academics that created the apps and only more recently and in a limited fashion, by other academics who specialize in mathematics apps. Thirdly, a Master of Education student, completing a course on mathematics education, used the ACAT review guide and thus would perhaps be more attuned to the theories and practices underpinning it than many classroom teachers. Finally, the authors of this paper conducted the evaluation of her use of the review guide that members of the writing team created. 
In identifying the limitations of the research to date we therefore both establish the parameters

within which we can claim the validity and reliability of our research, and also importantly identify future directions for our research. We have: begun to expand the use of ACAT to academic researchers not initially involved in its conception; used it on apps [Pattern Shapes; Click the Cube] not originally designed according to ACAT principles; and invited an independent reviewer to test the ACAT review guide. What is still is required is a larger scale "field test" of the guide by a range of new and experienced classroom practitioners that will enable us to fine tune the guide to make it more useful for teachers in evaluating apps in a range of contexts. A major final step in the development of ACAT and initially [Place Value Chart] is for us to research the experience of children using the app to fully validate our claims for the veracity of ACAT. Attaining these latter two goals is critical for the further development of ACAT and underpin a current application by the authors for research funding via a German Australia Research Cooperation Scheme. We hope to be able to report the outcomes of the research, conducted as part of the scheme, in future publications.

\section{References}

Alqahtani, M.M. \& Powell, A.B. (2017). Teachers' Instrumental Genesis and Their Geometrical Understanding in a Dynamic Geometry Environment. Digit Exp Math Educ, 3(1), 9-38. https://doi.org/10.1007/s40751-016-0025-5

Baccaglini-Frank, A. \& Maracci, M. (2015). Multi-Touch Technology and Preschoolers' Development of Number-Sense. Digit Exp Math Educ, 1(1), 7-27. https://doi.org/10.1007/s40751-015-0002-4

Carbonneau, K. J., Marley, S. C., \& Selig, J. P. (2013). A meta-analysis of the efficacy of teaching mathematics with concrete manipulatives. Journal of Educational Psychology, 105(2), 380-400.

Clements, D.H. (1999). 'Concrete' manipulatives, concrete ideas. Contemporary Issues in Early childhood, I(1), p. 45-60.

Clements, D. H., \& Battista, M. T. (1992). Geometry and spatial reasoning. In D. A. Grouws (Ed.), Handbook of research on Mathematics teaching and learning (pp. 420-464). New York: Macmillan.

Dick, T. P. (2008). Fidelity in Technological Tools for Mathematics Education. In G. W. Blume. a. M. K. Heid (Eds.), Research on Technology and the Teaching and Learning of Mathematics: Volume 2. Cases and Perspectives (pp. 333-339): Information Age Publishing.

Engeström, Y. (1987). Learning by expanding: An Activity - Theoretical Approach to Developmental Research. Retrieved from http://communication.ucsd.edu/MCA/Paper/Engestrom/expanding/toc.htm

Engestrom, Y., Miettinen, R., \& Punamaki, R.-L. (1999). Perspectives on Activity Theory. Cambridge, United Kingdom: Cambridge University Press.

Etzold, H., Kortenkamp, U., \& Ladel, S. (2018). ACAT-Review-Guide - Ein tätigkeitstheoretischer Blick auf die Beurteilung von Mathematik-Apps. In: S. Ladel, U. Kortenkamp, \& H. Etzold. Mathematik mit digitalen Medien - konkret. Ein Handbuch für Lehrpersonen der Primarstufe. Lernen, Lehren und Forschen mit digitalen Medien. Band 4. Münster: WTM. Verlag.

Giest, H. \& Lompscher, J. (2004). Tätigkeitstheoretische Überlegungen zu einer neuen Lernkultur. Sitzungsberichte der Leibniz-Sozietät 72, 101-123.

Highfield, K., \& Goodwin, K. (2013). Apps for mathematics learning: A review of 'Educational' Apps from the iTunes App Store. Paper presented at the Mathematics education: Yesterday, today and tomorrow (Proceedings of the $36^{\text {th }}$ annual conference of the Mathematics Education Research Group of Australasia), Melbourne, VIC.

Holgersson, I., Barendregt, W., Emanuelsson, J., Ottosson, T., Rietz, E., \& Lindström, B. (2016). Fingu-A Game to Support Children's Development of Arithmetic Competence: Theory, Design and Empirical Research. In P. S. Moyer-Packenham (Ed.), International Perspectives on Teaching and Learning Mathematics with Virtual Manipulatives, Mathematics Education in the Digital Era, 7. Netherlands: Springer.

Jorgensen, R. \& Larkin, K. (2017). Analysing the relationships between students and mathematics: A tale of two paradigms. Mathematics Education Research Journal. 29(1), 113-130 DOI: 10.1007/s13394-016-0183-1

Kaptelinin, V. (1996). Activity Theory: Implications for Human Computer Interaction. In B. Nardi (Ed.), Context and Consciousness: Activity Theory and Human Computer Interaction (3rd ed., pp. 103-116). 
Cambridge: MIT Press.

KMK (2013). The Education System in the Federal Republic of Germany. Retrieved from http://kmk.org/fileadmin/doc/Dokumentation/Bildungswesen_en_pdfs/primary.pdf

Ladel, S. and Kortenkamp, U. (2011). An Activity-Theoretic Approach to Multi-Touch Tools in Early Maths Learning. In: Proceedings of ATATEMLO 2011, Paris.

Ladel, S. \& Kortenkamp, U. (2012). An Activity-Theoretic Approach to Multi-Touch Tools in Early Mathematics Learning. International Journal of Technology in Mathematics Education, 20(1), p. $1-6$.

Ladel, S. and Kortenkamp, U. (2013). Designing a technology based learning environment for place value using artifact-centric activity theory. In A.M/ Lindmeier \& A. Heinze. (Eds.), Proceedings of the 37th conference of the International Group for the Psychology of Mathematics Education. Mathematics learning across the life span, volume 1, (pp.188-192).

Ladel, S. (2009). Multiple externe Repräsentationen (MERs) und deren Verknüpfung durch Computereinsatz. Zur Bedeutung für das Mathematiklernen im Anfangsunterricht. Hamburg: Verlag Dr. Kovac.

Ladel, S. (2018). Kombinierter Einsatz virtueller und physischer Materialien. Zur handlungsorientierten Unterstützung des Erwerbs mathematischer Kompetenzen. In B. Brandt \& H. Dausend (Eds.), Digitales Lernen in der Grundschule. Fachliche Lernprozesse anregen. Münster: Waxmann, p. 53-72.

Ladel, S. \& Kortenkamp, U. (2014). Number concepts — processes of internalization and externalization by the use of multi-touch technology. In U. Kortenkamp, B. Brandt, C. Benz, G. Krummheuer, S. Ladel, \& R. Vogel (Eds.), Early mathematics learning: Selected papers of the POEM 2012 conference (Chap. 15). New York: Springer-Verlag.

Ladel, S., \& Kortenkamp, U. (2016). Artifact-Centric Activity Theory-A Framework for the Analysis of the Design and Use of Virtual Manipulatives. In P. S. Moyer-Packenham (Ed.), International Perspectives on Teaching and Learning Mathematics with Virtual Manipulatives, Mathematics Education in the Digital Era, 7. Netherlands: Springer.

Larkin, K. \& Finger, G. (2011). Netbook computers as an appropriate solution for one-to-one computer use in primary schools. Australian Educational Computing, 26(1), 27-34.

Larkin, K. (2013). Mathematics Education. Is there an App for that? In: V. Steinle, L. Ball \& C. Bardini (Eds.). Mathematics Education: Yesterday, Today and Tomorrow. Proceedings of the 36th annual conference of the Mathematics Education Research Group of Australasia: Melbourne, (July 7-11, 2013)

Larkin, K. (2015). “An App! An App! My Kingdom for An App”: An 18-Month Quest to Determine Whether Apps Support Mathematical Knowledge Building. In T. Lowrie \& R. Jorgensen (Eds.), Digital Games and Mathematics Learning. Springer Netherlands.

Larkin, K. (2016). Geometry and iPads in Primary Schools: Does Their Usefulness Extend Beyond Tracing an Oblong? In P. S. Moyer-Packenham (Ed.), International Perspectives on Teaching and Learning Mathematics with Virtual Manipulatives, Mathematics Education in the Digital Era, 7. Netherlands: Springer.

Larkin K., Milford T. (2018) Using Cluster Analysis to Enhance Student Learning When Using Geometry Mathematics Apps. In: Ball L., Drijvers P., Ladel S., Siller HS., Tabach M., Vale C. (eds.), Uses of Technology in Primary and Secondary Mathematics Education. ICME-13 Monographs. Springer, Cham.

Larkin, K. \& Milford, T. (2018b). Mathematics Apps - Stormy With The Weather Clearing: Using Cluster Analysis To Enhance App Use In Mathematics Classrooms. In N. Calder, K. Larkin \& N. Sinclair (Eds.). Using mobile technologies in the teaching and learning of mathematics. Mathematics Education in the Digital Era. Springer.

Leontiev, A. N. (1981). The Problem of Activity in Psychology. In J. V. Wertsch (Ed.), The Concept of Activity in Soviet Psychology (pp. 37 - 71). New York: M.E. Sharpe.

Lommatsch, C., Tucker, S., Moyer-Packenham, P. \& Symanzik, J. (2018). Heatmap and Hierarchical Clustering Analysis to Highlight Changes in Young Children's Developmental Progressions Using Virtual Manipulative Mathematics Apps. In N. Calder, K. Larkin \& N. Sinclair (Eds.). Using mobile technologies in the teaching and learning of mathematics. Mathematics Education in the Digital Era. Springer

Lowrie, T., Logan, T., \& Ramful, A. (2017). Visuospatial training improves elementary students' mathematics performance. British Journal of Educational Psychology, Online first. DOI:10.1111/bjep.12142

Moyer-Packenham, P. S., \& Bolyard, J. J. (2016). Revisiting the definition of a virtual manipulative. In P. Moyer-Packenham (Ed.) International Perspectives on Teaching and Learning mathematics with Virtual Manipulatives, Mathematics Education in the Digital Era, 7 (pp. 3-23). Springer International Publishing.

Moyer-Packenham et al. (2016). The role of affordances in children's learning performance and efficiency when using virtual manipulative mathematics touch-screen apps. Mathematics Education and Mobile 
Technologies - Special Issue of the Mathematics Education and Research Journal, 28(1), 79-105. doi:10.1007/s13394-015-0161-z

Moyer-Packenham, P. S., Salkind, G., \& Bolyard, J. J. (2008). Virtual manipulatives used by K-8 teachers for mathematics instruction: Considering mathematical, cognitive, and pedagogical fidelity. Contemporary Issues in Technology and Teacher Education, 8(3), 202-218.

Namukasa, I. K., Gadanidis, G., Sarina, V., Scucuglia, S., \& Aryee, K. (2016). Selection of Apps for Teaching Difficult Mathematics Topic: An Instrument to Evaluate Touch-Screen Tablet and Smartphone Mathematics Apps. In P. S. Moyer-Packenham (Ed.), International Perspectives on Teaching and Learning Mathematics with Virtual Manipulatives, Mathematics Education in the Digital Era, 7. Netherlands: Springer.

Nardi, B. A. (1996). Activity Theory and Human-Computer Interaction. In B. A. Nardi (Ed.), Context and Consciousness. Activity Theory and Human-Computer Interaction (3rd ed., pp. 7-16). London, England: MIT Press.

National Council of Teachers of Mathematics. (2018). Principles and Standards/Geometry. Retrieved from http://www.nctm.org/Standards-and-Positions/Principles-and-Standards/Geometry/

Özel, S. (2012). Learning Rational Numbers: An Experimental Multi-Model Representation Approach Via Technology. Mediterranean Journal for Research in Mathematics Education, 11(1-2), 59-79.

Papadakis, S., Kalogiannakis, M., \& Zaranis, N. (2018). Educational apps from the Android Google Play for Greek preschoolers: A systematic review. Computers \& Education, 116, 139-160.

Papic, M., Mulligan, J. T., \& Mitchelmore, M. C. (2011). Assessing the development of preschoolers mathematical patterning. Journal for Research in Mathematics Education, 42, 237-268.

Pimm, D. (1995). Symbols and Meaning in School Mathematics. Routledge. New York.

PocketGamer.biz. (2018). App store metrics. Retrieved from http://www.pocketgamer.biz/metrics/app-store/

Powell, S. (2014). Choosing iPad Apps With a Purpose: Aligning Skills and Standards. Teaching Exceptional Children, 47(1), 20-26.

Scanlon, E., \& Issroff, K. (2005). Activity Theory and Higher Education: evaluating learning technologies. Journal of Computer Assisted Learning, 21, 430 - 439.

Sinclair, N., \& Bruce, C. D. (2015). New opportunities in geometry education at the primary school. ZDM Mathematics Education, 47, 319-329. doi:10.1007/s11858-015-0693-4

Sinclair, N., Chorney, S., \& Rodney, S. (2016). Rhythm in number: exploring the affective, social and mathematical dimensions of using TouchCounts. Mathematics Education and Mobile Technologies Special Issue of the Mathematics Education and Research Journal, 28(1), 31-51. doi:10.1007/s13394-0150154-y

Sinclair, N. \& Pimm, D. (2015). Mathematics using multiple sense: Developing finger gnosis with three-and four-year-olds in an era of multi-touch technologies. Asia-Pacific Journal of Research in Early Childhood Education, 9(3), 99-109.

Soury-Lavergne, S. (2016). Duos of artefacts, connecting technology and manipulatives to enhance mathematical learning. In Proceedings of the $13^{\text {th }}$ International Congress on Mathematical Education. Hamburg.

Tucker, S. (2016). The Modification of Attributes, Affordances, Abilities, and Distance for Learning Framework and Its Applications to Interactions with Mathematics Virtual Manipulatives. In P. S. MoyerPackenham (Ed.), International Perspectives on Teaching and Learning Mathematics with Virtual Manipulatives, Mathematics Education in the Digital Era, 7. Netherlands: Springer.

Tucker, S. (2017). I Thought This Was a Study on Math Games: Attribute Modification in Children's Interactions with Mathematics Apps. Education sciences, 7(50).

Teach Thought. (2017). 12 of the Best Maths Apps. Retrieved from http://www.teachthought.com/thefuture-of-learning/technology/12-of-the-best-math-apps-for-kids/

Uttal, D. (2003). On the Relation Between Play and Symbolic Thought. The Case of Mathematics Manipulatives. In O. Saracho \& B. Spodek (Eds.). Contemporary Perspectives on Play in Early Childhood Education. Information Age Publishing.

Uttal, D., \& Cohen, C. (2012). Spatial Thinking and STEM Education: When, Why, and How? Psychology of Learning and Motivation - Advances in Research and Theory (Vol. 57, pp. 148-178).

van Hiele, P. M. (1999). "Developing Geometric Thinking through Activities That Begin with Play." Teaching Children Mathematics, 5(6), 310-316.

Voida, S., Mynatt, E., \& MacIntyre, B. (2007): Supporting activity in desktop and ubiquitous computing. In: V. Kaptelinin \& M. Czerwinski (eds.), Beyond the desktop metaphor: Designing integrated digital work environments. Cambridge, Massachusetts: MIT Press (pp. 195-222).

Zbiek, R. M., Heid, M. K., Blume, G. W., \& Dick, T. P. (2007). Research on Technology in Mathematics Education: A Perspective of Constructs. In F. K. Lester (Ed.), Second Handbook of Research on Mathematics Teaching and Learning (pp. 1169-1207): National Council of Teachers of Mathematics. 


\title{
Using the ACAT Framework to evaluate the design of two geometry apps: An exploratory study.
}

Authors

Kevin Larkin. School of Education and Professional Studies, Griffith University, Gold Coast, Australia.

Email k.larkin@griffith.edu.au

Phone +61428 566708

Orcid 0000-0002-8704-1272

Ulrich Kortenkamp. Institute of Mathematics, Potsdam University, Germany.

Silke Ladel. University of Education Schwäbisch Gmünd, Germany.

Heiko Etzold. Institute of Mathematics, Potsdam University, Germany.

\begin{abstract}
It is an increasingly common phenomenon that elementary school students are using mobile applications (apps) in their mathematics classrooms. Classroom teachers, who are using apps, require a tool, or a set of tools, to help them determine whether or not apps are appropriate and how enhanced educational outcomes can be achieved via their use. In this article we investigate whether Artifact Centric Activity Theory (ACAT) can be used to create a useful tool for evaluating apps, present a review guide based on the theory and test it using a randomly selected geometry app [Pattern Shapes] built upon different (if any at all) design principles. In doing so we broaden the scope of ACAT by investigating a geometry app that has additional requirements in terms of accuracy of external representations, and depictions of mathematical properties (e.g. reflections and rotations), than is the case for place value concepts in [Place Value Chart] which was created using ACAT principles and has been the primary app evaluated using ACAT. We further expand the use of ACAT via an independent assessment of a second app [Click the Cube] by a novice, using the ACAT review guide. Based on our latest research, we argue that ACAT is highly useful for evaluating any mathematics app and this is a critical contribution if the evaluation of apps is to move beyond academic circles and start to impact student learning and teacher pedagogy in mathematics.
\end{abstract}

Keywords: Mathematics education; Mathematics apps; Activity Theory; Artifact-Centric Activity Theory; geometry; App design; App reviews 


\title{
ACAT Review Guide - An activity theory approach to reviewing math apps.
}

\author{
Heiko Etzold \& Ulrich Kortenkamp, University of Potsdam \\ Silke Ladel, University of Education Schwäbisch Gmünd \\ Kevin Larkin, Griffith University
}

\section{Introduction}

Mathematics education as a Design Science (Wittmann 1995) has the responsibility to help judge and review material for teaching and learning mathematics, including digital ones like computer software and apps for mobile devices. This review guide has been developed to fulfill that responsibility. The usual approach to evaluating the suitability of apps for teaching and learning are catalogues and categorizations, resulting in rankings (cf. Highfield \& Goodwin, 2013). However, these are not particularly useful to give hints about the suitability of the app for a certain subject matter or particular classroom situation. We propose another approach, a theory-guided approach to evaluating Apps, without ranking them or even labeling them as "good" or "bad", but as a guideline to find ways to judge the deployment of specific apps in the classroom.

The theoretical basis for our review guide is activity theory, more specifically the ACAT model (Artifact Centric Activity Theory, see Ladel \& Kortenkamp, 2014). This model describes network of a subject (usually a student), an object (the mathematical subject matter), the mediating artifact (in our case an App used by the student to work with the mathematical content), as well as rules (describing how the app should behave based on the mathematical object) and the group (the whole classroom situation).

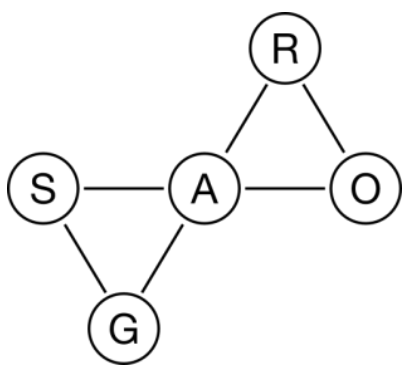

It is not necessary to know the details of the psychological and pedagogical theory in order to understand and use the following guide. A helpful introduction for those who want to know more can be the text of Kaptelinin (2014). For every step of the guide we will give background information concerning the theoretical foundation.

\section{The Review Guide}

This review guide is organised into five steps that can be associated to five foci in the ACAT model. It is mandatory to follow these steps in the given order.

Starting from the mathematical content we will analyse how students work with the app. From that we will infer whether the app is able to help in supporting the acquisition of the desired content. Finally concrete classroom situations can be discussed that are suitable for using the app. Based on this approach it can happen that the same app is perfectly suited for specific teaching situations, but not for others, even if the same topic is being handled. The step-by-step approach will guide the review to the essential and fundamental questions immediately. This can cause an early conclusion of the review after each step, if it is foreseeable that the app is not suitable for the planned instruction.

Thus, the review guide structures the decision process and makes it transparent to teachers. For every step we list the possible data sources that can be used. 


\section{Step 1: What is the mathematical object of the app?}

Identify the mathematical object i.e. which concept, content or mathematics process is targeted by the app.

It is important to note that each app can address one or several mathematical objects. In the case of several objects, separate reviews for each object are necessary as each object will emphasize different learning facets and will therefore vary in efficacy across this range of facets.

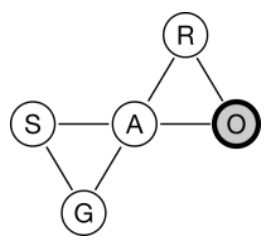

\section{Possible Sources}

- The app's title and its official description at iTunes or Google Play

- Additional material provided (e.g. downloadable worksheets)

- External references (e.g. recommendations by peers who have used the app)

- Trials of the app

\section{Background}

A central principle of activity theory is object orientation. As actions only exist (or at least can only be recognized) in relation to a specific object, activities are therefore directed towards the attainment of an object. Consequently, actions of students within an app can only be understood if the (mathematical) object of their actions is known. In this instance, the mathematical object is understanding how shapes can be manipulated to create new shapes.

\section{Step 2: How do students interact with the mathematical object, mediated by the app?}

Discuss what kind of interaction with the mathematical object the app offers to the students. For this, it is necessary to look at the separate interactions between subject and artifact, as well as between artifact and object. In examining these interactions we can ask: What actions does the app support? How does the app represent the mathematical object? How does the object influence the "behavior" of the app? What can students experience through the above?

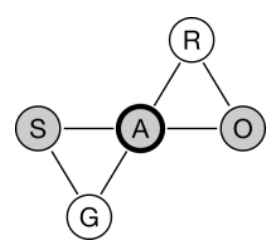

\section{Possible Sources}

- Own systematic testing of the app

\section{Background}

When designing an app, formulating the rules for user interaction would occur at this stage in the ACAT design process. As we are analyzing an existing app we immediately examine user interaction.

A core component of interest Activity Theory, and thus ACAT, is the process of Internalization and Externalization. External actions of the subject, such as pinch-to-zoom gestures to scale a city map represent internal actions, in this case dilations, that in turn are representations of student understanding. In a similar way, external actions can create internal representations. In order to understand this user interaction more fully, and to refer more concisely to the mathematical object, it is useful to sub-divide this process between subject and object at their respective interactions with the artifact (Ladel \& Kortenkamp, 2014). 
The guiding questions thus follow back and forth between subject, artifact, object:

$\mathrm{S} \rightarrow \mathrm{A}$ : Which actions does the app support?

$\mathrm{A} \rightarrow \mathrm{O}:$ How does the app represent the mathematical object?

$\mathrm{O} \rightarrow \mathrm{A}:$ How does the object influence the "behavior" of the app?

$\mathrm{A} \rightarrow \mathrm{S}:$ What can students experience through the above?

\section{Step 3: How does the interaction develop?}

Structure the possible interactions by categorizing them into activities, actions, and operations (Leontiev, 1981):

- Activities are superordinate interactions directed by the subject's motives, e.g. reading a city map to determine direction of travel;

- Actions are targeted, individual interactions, e.g. changing a map's

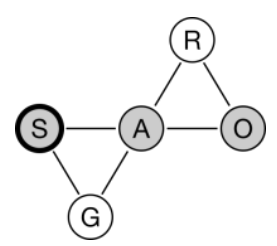
scale to get a more detail view of a certain section of a map; and

- Operations are internalized interactions that do not need further cogitation and can be governed by instrumental constraints, e.g. the actual execution of pinch-to-zoom gesture to scale or of the drag gesture to move the map.

Elaborate upon how this categorization changes while using the app as actions can become operations during the learning process and allow for the creation of new actions in turn.

\section{Possible Sources}

- Discussion of hypothetical scenarios

- Empirical tests

\section{Background}

At this point in the review process a specific view on the hierarchy of activities, actions and operations as another principle of activity theory is appropriate. At the same time, conclusions about possible developments of students' learning can be drawn. A successful learning process is characterized by actions becoming operations in order to enable more complex actions.

\section{Step 4: Is the app suitable for teaching and learning the mathematical object?}

Compare the use of the app for the specific mathematical object, as uncovered in the guide, with knowledge from mathematics specific pedagogy, the discipline of mathematics, and psychology regarding the teaching and learning of the mathematics object in question. In other words, do the interactions identified and analyzed in Steps 2 and 3 support the desired ideas, experiences, conceptions, and competencies, as required by quality mathematics educa-

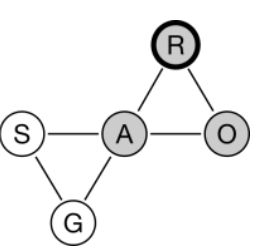
tion? In addition, is the technological design suitable for learning according to theories of high quality Human Computer Interaction (HCI) design?

Possible sources

- Syntheses of the discussion above 
- Scientific background literature and references

\section{Background}

The design of an app is guided by rules in the ACAT model, which in turn are guided by knowledge from mathematics education, HCI design, etc. This ensures that the app is indeed supporting student learning, and that the targeted mathematical content can be taught or learned via its use.

\section{Step 5: How can the app be used in classroom instruction?}

Illustrate how the app might be used in the classroom. You can use the following questions as a guide:

- Can the app be used for individual, partner or small group work or is it limited to only one of these types of social interaction?

- How can classroom discussions / collaborations / and interactions be

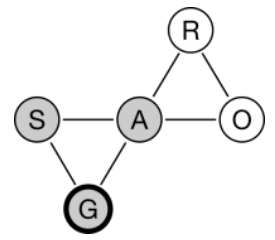
fostered through activity with the app, either directly or indirectly?

- What are possible provocations or tasks the teacher can provide students?

- Which kinds of differentiation, and which levels of difficulty, are possible?

- Is it an app for instructive (drill and practice) activities or is it discovery based and designed to introduce students to new content or to construct new ideas?

- Which requirements and competences are necessary to use the app?

Possible sources

- Additional teacher's material

- Trials with students

- Results from experimental studies by other researchers

- Imagination

\section{Background}

Within both Activity Theory and ACAT, learning is never understandable as a pure individual activity of a student. It must always be seen in a social and corporate context where learning is common work. As noted by Giest and Lompscher (2004), in the classroom there is always a "pädagogisches Gesamtsubjekt" such that the activities always occur in the contexts of interaction, communication or cooperation, including relationships between learners, teachers, and other participants. 
Etzold, Kortenkamp, Ladel, Larkin - ACAT-Review Guide

\section{References}

Giest, H. \& Lompscher, J. (2004). Tätigkeitstheoretische Überlegungen zu einer neuen Lernkultur. In: Sitzungsberichte der Leibniz-Sozietät 72, pp. 101 - 123.

Highfield, K. \& Goodwin, K. (2013). Apps for mathematics learning: A review of 'Educational' Apps from the iTunes App Store. Paper presented at the Mathematics education: Yesterday, today and tomorrow (Proceedings of the 36th annual conference of the Mathematics Education Research Group of Australasia), Melbourne, VIC.

Kaptelinin, V. (2014). Activity Theory. In: Armin Zahirovic et al. (Eds.), The Encyclopedia of Human-Computer Interaction, $2^{\text {nd }}$ edition. The Interaction Design Foundation.

Ladel, Silke und Ulrich Kortenkamp (2014). Tätigkeitsorientiert zu einem flexiblen Verständnis von Stellenwerten - Ein Ansatz aus Sicht der Artefact-Centric Activity Theory. In: Von Audiopodcast bis Zahlensinn. Silke Ladel and Christoph Schreiber (Eds.), vol. 2. Lernen, Lehren und Forschen mit digitalen Medien. Münster: WTM Verlag, pp. 151 $-176$.

Leontiev, A. N. (1981). The Problem of Activity in Psychology. In J. V. Wertsch (Ed.), The Concept of Activity in Soviet Psychology (pp. 37 - 71). New York: M.E. Sharpe.

Wittmann, E.C. (1995). Mathematics Education as a 'Design Science'. In: Educational Studies in Mathematics 29, pp. 355 - 374. 


\section{ACAT Review for App [Click the Cube]}

\section{What is the mathematical object of the app?}

The mathematical objects of the app are cubes and their nets. The app focuses on the relation between 2D and 3D representations of cubes and should enable students to develop better spatial abilities.

\section{How do students interact with the mathematical object, mediated by the app?}

The app is organised into three parts. In the first part students are asked to decide whether various nets are nets of a cube or not. In the second part students are required to complete unfinished nets of cubes. In the third part they color a net to match a given cube. In all three parts the screen is divided into two areas. The left area contains the task and an overview of the medals and stars collected so far for correct answers. The right area shows the current cube or net for the task and it is possible to manipulate the object using various gestures on the screen. In the first part the user is presented with a slightly folded net of cube. The user can rotate and scale the net and use a slider to fold or unfold it gradually. The first operation, rotation, is done through pan gestures. It is not a requirement to start the gesture on the net as it is possible to start anywhere in the right area, allowing the student to see the full net in rotation. Through this gesture the user can see the object from all perspectives. With a pinch-to-zoom gesture the user can change the scale of the net, to enlarge or shrink it on the screen. This enables the student to 
find the optimal position of the object for inspection. He or she can zoom into critical areas to obtain further information. The third operation is to use the slider, moving its indicator to the left or right with the finger. Moving the finger to the right will fold the net, that is, diminish the spatial angle between the faces of the net until it is at 90 degrees, moving the indicator to the left will open up the net until it is flat. Using the slider enables the user to extend their spatial impression of the net and encourages students to continue the folding or unfolding of the net mentally.

The net of the cube is colored in white on one side and grey on the other. When folded, the grey side is on the inside and the white side is on the outside. Thus, a fully folded cube will appear white. The more the users move the slider to the right (thus folding the cube), the fewer number of points (stars) they receive for a correct answer. Not touching the slider will maximise the points if the correct answer is given when pressing the "Yes" or "No" button. Rotating or scaling the object does not influence the number of points. The reduction in points for using the slider is used consistently in all parts of the app. In order to receive as many points as possible, users are motivated not to use the visualized folding, but to find the answer with mental operations.

To start a new task, and to check or choose the answer, a user has to touch the corresponding blue words on the left side of the screen. Subsequently, an animation of the folding is shown on the right side. If two faces coincide this fact is highlighted in red. The user can still use the slider after this animation to further inspect the net and, if applicable, understand their mistake.

If enough stars have been awarded for an answer, the user will earn a medal. A total of four medals is possible.

The second part of the app requires the student to complete a net of cube by adding missing squares. The new squares are glued automatically to the existing net if they are brought into the vicinity of an edge. At some edges it is not possible to connect a square. To check the current net for correctness the user presses the "Check" button. This will determine whether a correct net has been formed and at the same time the folding process will be demonstrated with an animation in the right area of the screen. Adding squares is only possible when the net is fully flat (the starting configuration in this and the next part of the app). Adding a missing square to the net is achieved by dragging the free square from its original position to the intended edge. If it is impossible to add the square there, the user is required to inspect the rules for nets of cubes more closely.

The third part of the app is concerned with coloring a given net of a cube. In the task area on the left a cube is shown, which can be rotated and scaled for inspection of all of its sides, using the same gestures as in part 1 . Seven different colored circles, that can be used to color the net, are shown at the top of the screen. In order to color the net, a user has to drag the colored circle from the top of the screen onto the square that should be colored. Again, it is possible to use rotation and scaling as well as the slider to control the amount of folding. The task for the user is to color the net such that its corresponding cube is colored in the same way as the "task cube" on the left. After the solution has been checked it is possible to rotate both cubes to find the difference, if there is one. 


\section{ACAT-Review-Guide}

In general, the app provides the means to create a complete (mental) image of the cube or its net. The various interactions that are possible allow for an informed decision by the user about how much help is needed to solve each task. It is possible to use the app to interact with the cube or cube net for further inspection, but it is not necessary to solve the tasks (with the exception of rotating the task cube in part 3).

\section{How does the interaction develop?}

The user is operating mainly in the mind to act on the mathematical objects and has to fold the net mentally in order to determine whether it is the net of a cube, where to add the missing face, or how to rotate the cube mentally to assign the correct color. So the app is motivating "mental geometry" in phases as described by Weigand (2013) i.e. (phase 1) presenting the task; (phase 2) imagination and mental operations, and (phase 3) presenting the solution. In phases 1 and 3, staged help may be available to simplify the activities. The second phase, on the other hand, should happen mentally without any aids. Preliminary stages of mental geometry or preparatory activities can include further aids for the second phase, for example gestures, geometric models for illustration or alternate solutions like figures.

In the app we consider, a figure of the net is shown in the task phase (1), which could be used for mental geometry immediately. The subject (i.e. the user) can rotate or scale the initial situation in order to be better prepared for phase 2 . It might be the case that this already interferes with the second phase which should be mastered without a tool. In circumstances where the subject is not able to work on the task after it has been presented, the app offers interactive representations and acts as a tool for a preliminary stage of solving mental geometry tasks by visualizing them. The rotation and scaling operations allow the subject to create visualizations from various perspectives that they can register mentally and might enable them to solve the task without any help the next time. Also, when touching the button for registering the solution, the animation of the folding is shown that can help the subject to check the correctness of their mental operations. As the app does not proceed to the next exercise automatically, but rather requires an active selection of the next task, it is still possible to repeat and confirm the actions and operations that lead to the solution. The app stimulates mental operations in various ways, so I consider it as a tool that helps students to acquire the competency of doing mental geometry.

Possible Improvements of the App:

When building a net it is possible to place a square on, or rather in, the net. Sometimes this leads to flickering of overlapping faces. For a better understanding it would be helpful to prevent the possibility of overlapping faces.

Sometimes it is not possible to add a square at a certain edge, for example if this leads to a 2 by 2 square. While this is a reasonable restriction it can be irritating to students. A possible improvement could be an animation where a misplaced square is moving away from a forbidden edge after placement, in order to highlight that there is a problem with this placement. This could encourage the users to reconsider the conditions of cube nets in that situation. 
In order to simplify the user interaction in the third part of the App the coloring of squares could be realized through a tap-tap gesture (first tapping the color, then the square) instead of a drag gesture (dragging the color to the square).

120 It does not matter in the app whether a square is colored from the inside or the outside. However,

121 it is difficult to see whether a colored square will be on the inside or the outside in the folded

122 cube. To avoid confusion the contrast between the inside and the outside should be increased. These aspects have been observed in tests with several people who had difficulty coloring the net.

\section{Is the app suitable for teaching and learning the mathematical object?}

126 The app seems to be beneficial in developing the ability to do mental geometry and as such also to foster spatial abilities. In particular the visualization of the connection between a net and a 3D object is helpful for the work with cube nets. The user can apply and check their knowledge about cube nets and extend their abilities in mental folding and in the mental imagination of this process. As a consequence the app is suitable for practice phases. An introduction to the topic of (cube) nets should precede the use of the app. It is important to develop these abilities in class 3/4 (age 8-9), as it is a foundation for later teaching. For example, calculating surface areas of composite bodies (e.g. cuboids with an attached cylinder) is a topic where students show difficulties. It is a common mistake to just add the areas of the two nets without removing faces where the two bodies touch. As one cause for this can be a lack of spatial ability, the app is a helpful tool to prepare students to avoid such mistakes.

137 Using the app also opens new ways to work with cube nets and should be seen as a supplement to cut-out nets and crafting cubes from these. The app cannot replace the haptic experience, but offers training that could not be done with paper or cardboard material or images alone (See Bruner's EIS approach, 1988).

141 Furthermore, the app allows for differentiated learning. Again it is possible to refer to the three

142 phases in mental geometry. In the first phase the task is presented together with a net. For higher achieving students (in this particular discipline) this can be solved solely through mental operations without further aids. Those students who need more assistance can use the on-screen operations for rotating and scaling the nets for a change of perspective. If this is not enough, they can also use the slider to fold the net slightly or completely, according to their needs. In this way the app can help to improve the mental geometry abilities of all users, starting at various levels of ability.

149 In conclusion the app seems to be well suited for the subject of cube nets and to help students

150 to develop their spatial abilities while they work on objects in a way differentiated by their 151 current abilities.

\section{5. How can the app be used in classroom instruction?}

153 In school education there are several options to use the app. As the exercise tasks are delivered

154 by the app, it can be used for individual work of students. For the teacher it is not necessary to 


\section{ACAT-Review-Guide}

provide examples so they can take care of certain students, i.e. low achieving ones. These exercise sequences can be repeated several times during the school year. It is also possible to use this app for learning stations with the topic of cubes. The students would be able to talk about and compare their strategies. Possibly it is also usable for saving time and materials after the introduction of creating boxes etc.

\section{There are, however, some difficulties when using the app:}

For example, with a class size of 30 pupils, it will be difficult for the teacher to address the problems of each individual that result from using the app. On the basis of the medals it is not possible to say anything about the students' skills. This is a critique of collecting stars and medals as points. If the user takes help when interacting with the app, they only get a part of a star. Because of filling the stars, it is not discernible whether the student solved 20 tasks with help or only 10 tasks without help as both options result in a medal. A better way would be a diagnosis tool where a teacher can see the student's problems in order to respond adequately.

\section{Additional notes:}

Because there are only 11 different cube nets, it could be possible that users sometimes know all of them and they only tap the right answer without thinking about it. That should be prevented by a semi folded net and a random alignment at beginning, but it is not to be ruled out (see Huhmann, 2013). One way to expand the app is to supplement it by cuboid nets. You can give similar tasks to be sure that students are not getting answers based on memorized learning. The mental folding of cuboid nets also offers new aspects, i.e. opposite edges with non equal length. There are also 54 cuboid nets so the option to memorize them has been reduced.

In the second part the free square is difficult to move. This usability isn't optimal and should be revised.

Another expansion could be an option for color-blinded people. For this purpose all colors can be assigned by a unique structure.

The rewarding of correct answers using medals isn't enjoyable when using the app alone and once you have got all four medals there is no more progress. To solve this, there could be several stars (i.e. several colors), but that also depends on the target (diagnosis vs. collecting points).

One final point: Is it meaningful to reduce the score even when rotating the cube net? According to mental geometry (phase 2) it shouldn't be allowed to rotate, but it contributes to understand the situation. One extension of the app (maybe for higher grades) could be to show the net and require the user to do any further operation mentally. With a correct answer you earn a yellow star and if you used the rotation option you only get a full blue star for a right answer.

\section{Note}

This is a translation of a German review by Sarah Stein, University of Potsdam. Translation by Heiko Etzold, Ulrich Kortenkamp and Kevin Larkin. 
Sarah Stein

\section{References}

194 Bruner, J. (1988): On Cognitive Development. In: Jerome S. Bruner, Rose R. Oliver and Stuttgart: Klett-Cotta, p. 21-54.

Huhmann, T. (2013). What influence can computer animations have on spatial perception development? Heidelberg: Springer Spectrum.

Weigand, H. (2013). Didactics of Geometry for Secondary Education 1. Heidelberg: Spektrum Verlag. 